\title{
Primera centuria de la presencia de Hideyo Noguchi en el Perú.
}

\author{
First century of Hideyo Noguchi's presence in Peru.
}

\author{
Lizardo Cruzado ${ }^{1,2}$
}

\section{RESUMEN}

En este año 2020 se conmemora un siglo de la presencia física de Hideyo Noguchi en el Perú. Noguchi arribó en el marco de sus investigaciones científicas acerca de la fiebre amarilla que asolaba el norte de nuestra patria. Aquella época de epidemia e incuria, de penuria y descalabro de diversos órdenes en el tejido social, fue similar a la circunstancia que ahora nos toca vivir, y por ende hoy es necesario recordar la imagen inspiradora de este médico y prohombre, no exento de complejidades ni de errores en su naturaleza humana, pero dotado de profunda convicción, espíritu de sacrificio y entrega a la humanidad doliente a través de la ciencia. La centuria de la presencia física de Hideyo Noguchi en el Perú motiva el boceto de este perfil biográfico.

PALABRAS CLAVE: Biografía; Japón; Perú; Historia de la Medicina.

\section{SUMMARY}

This year, 2020, we commemorate the $100^{\text {th }}$ Anniversary of the physical presence of Hideyo Noguchi in Peru. He arrived here a century ago in the context of his scientific research about the yellow fever that ravaged the northern area of our country. Such period, very similar to the time we live in nowadays, was a time of epidemic and neglect, of hardship and misfortune of various orders in the social fabric of our country. Therefore, today it is necessary to remember the inspiring image of this physician and great man, not without complexities or errors in his human nature, but endowed with deep convictions, spirit of sacrifice and dedication to the suffering humanity through science. The century of the physical presence of Hideyo Noguchi among us, motivates the sketch of this biographical profile.

KEYWORDS: Biography; Japan; Peru; History of medicine.

\section{INTRODUCCIÓN}

Hideyo Noguchi es, sin duda, el científico japonés más famoso (1). Más de cien biografías suyas han sido publicadas en japonés (2) y muchas otras adicionalmente en los Estados Unidos de América, donde desarrolló la mayor parte de su proficua labor científica: su primera biografía allí fue publicada apenas tres años luego de su muerte (3) y varias han sido editadas hasta reciente época (4-6). La imagen de Hideyo Noguchi ha sido la primera de un científico nipón en aparecer en un billete, el de mayor circulación en el Japón, el de 1000 yenes (7) (figura 1), -lo que no deja de ser algo sutilmente irónico dada la pobreza que lo acompañó desde sus orígenes y en gran parte de su vida - y ha sido igualmente personaje de diversos

1 Departamento de Emergencia, Instituto Nacional de Salud Mental "Honorio Delgado - Hideyo Noguchi”. Lima, Perú.

2 Facultad de Medicina Alberto Hurtado. Universidad Peruana Cayetano Heredia. Lima, Perú. 


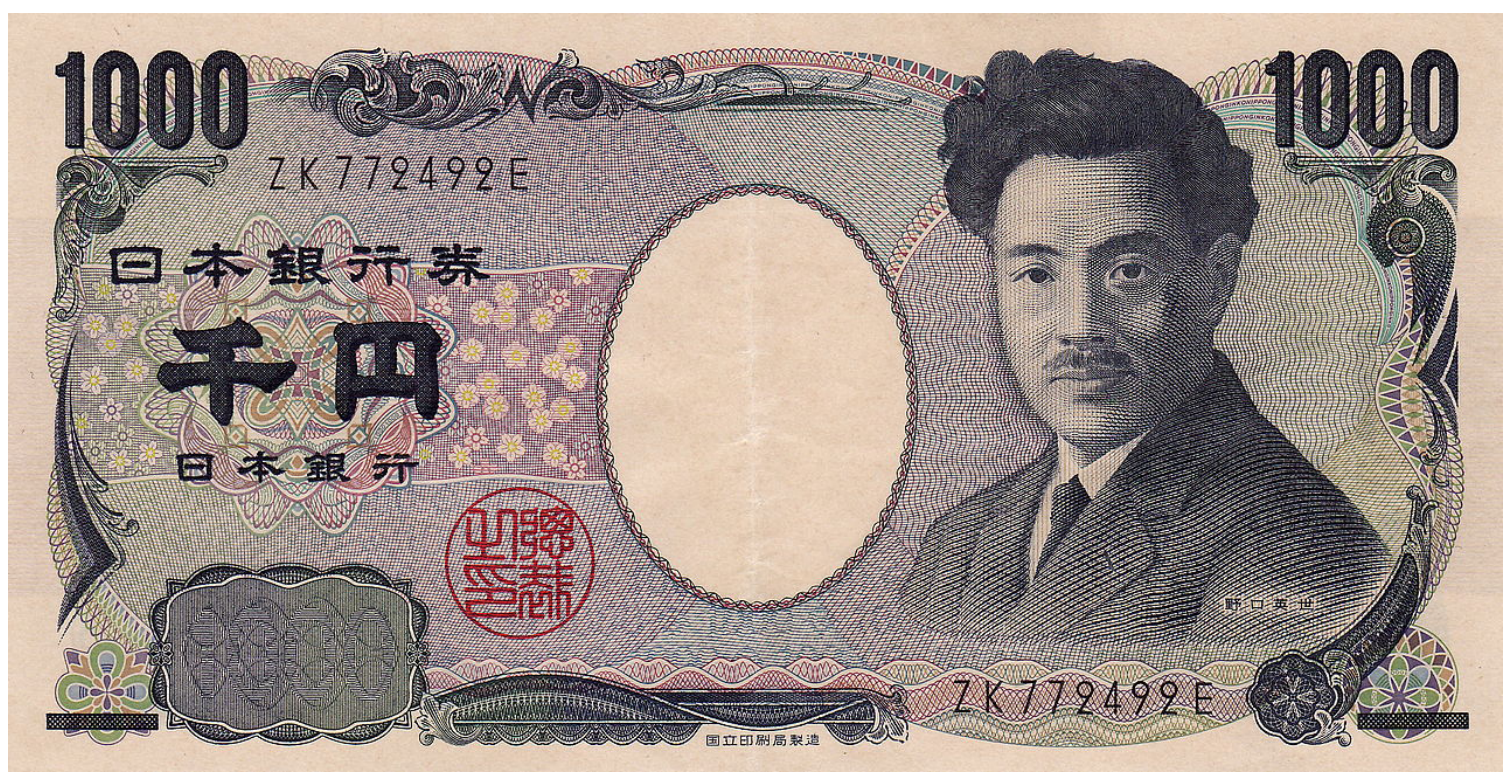

Figura 1. Billete japonés actual de 1000 yenes con la imagen de Hideyo Noguchi. (Fuente: https:// en.wikipedia.org/wiki/Hideyo_Noguchi\#/media/File:1000_yen_banknote_2004.jpg)

"mangas" y "animes" (figura 2). En nuestro país, las publicaciones acerca de Hideyo Noguchi son escasas (8-11).

Aunque en nuestro medio el nombre de Hideyo Noguchi está indesligablemente ligado al Instituto Nacional de Salud Mental de nuestro país, del que es epónimo junto a Honorio Delgado (8), es frecuente que se ignore el motivo de su nombradía-y lamentablemente no solo entre la población llana- por lo que su nombre deviene en un epónimo vacuo e informe. La biografía médica es un género historiográfico muy antiguo, anterior incluso a la propia disciplina y que tiene una larga tradición (12). En tal sentido, más allá de las tentaciones hagiográficas comprensibles y frecuentes, la biografía médica cumple un rol de primer orden al describir la tensión entre la singularidad del individuo concreto con su trayectoria vital única e irrepetible, y su representatividad como exponente de determinada época y contexto sociocultural temporal (12); es decir, la biografía añade un elemento humanizador a la historia de la medicina, insoslayable e insustituible por cuanto la medicina es una actividad inalienablemente humana.

Al cumplirse cien años de la visita de Hideyo Noguchi a nuestro país, en misión científica para el estudio de la epidemia de fiebre amarilla que asolaba el departamento de Piura en el norte peruano (11), es conveniente reencontrar la imagen biográfica e histórica de este prohombre japonés, el primer científico del lejano oriente que vino a América Latina (9) (llegó a visitar aparte de nuestro país también México, Ecuador, Brasil, Panamá y Argentina) en épocas similares a la actual, de infección y epidemia, de carencia y penuria, pero a la vez de denodado esfuerzo y compromiso humano y científico.

\section{SEISAKu (Japón, 1876-1900)}

Nació Hideyo Noguchi el 24 de noviembre del año de $1876,9^{\circ}$ año de la era Meiji (8) (es importante saber que en el Japón, al cambiar de emperador, se inicia una nueva época y se reinicia el calendario) (13). El emperador Meiji instauró en su país una amplia serie de transformaciones sociopolíticas, económicas y culturales, luego de una prolongada época en que el Japón tuvo cerradas sus fronteras a todo influjo extranjero y mantuvo estructuras rígidamente feudales. Se introdujeron reformas en el sistema de gobierno, las estructuras de producción, las relaciones políticas y diplomáticas y hasta en costumbres y usos culturales. Por ejemplo, la Universidad de Tokio, la primera del país, fue fundada recién en 1877. Asimismo, además de su nombre propio, las personas empezaron a tener oficialmente el equivalente de un apellido (13).

En la isla Honshū, la más grande de ese Japón desmedrado y rural, en la pequeña aldea de Sajogata, localidad de Inawashiro, prefectura de Fukushima, al pie del monte Bandai y a orillas de lago también llamado Inawashiro, vio la luz el niño Noguchi 


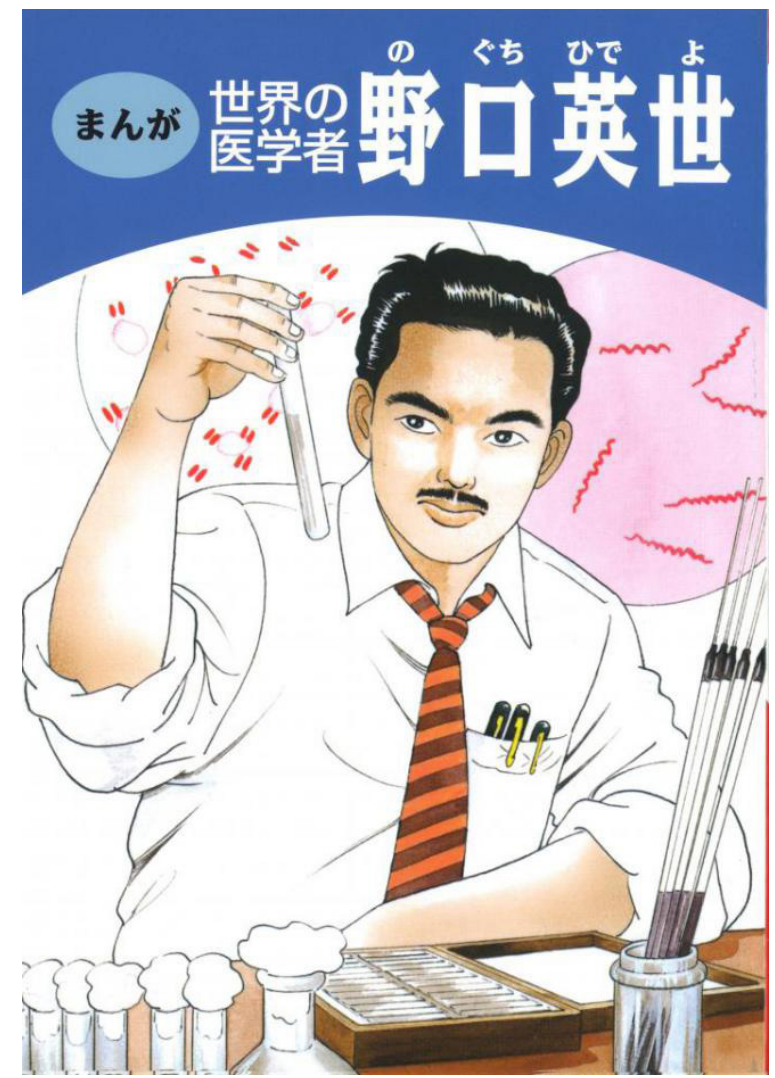

Figura 2. "El científico del mundo: Hideyo Noguchi" (まんが 世界の医学者 野口英世)

Uno de los muchos "mangas" inspirados en su figura. Nótese la mano izquierda siempre disimuladamente oculta. (Fuente: https://www.noguchihideyo.or.jp/about/ shop.php)

(el nombre que recibió al nacer fue Seisaku) (14). Sus padres, Shika y Sayosuke, eran campesinos muy humildes y analfabetos, además el padre era alcohólico y usualmente ausente del hogar (8). La madre debía trabajar largas jornadas en el cultivo y cosecha de arroz y dejaba al pequeño Seisaku, de año y medio, al cuidado de su hermana mayor Inu, de pocos años de edad. En un descuido, el pequeño que se aventuraba a conocer su pequeño mundo cayó de bruces sobre el fogón con carbones encendidos: sus gritos permitieron que sea rescatado, pero con varias quemaduras en el cuerpo: la más grave había reducido su mano izquierda a un amasijo informe (15). Se recuperó con los cuidados disponibles de la medicina tradicional japonesa y logró sobrevivir. Se asume que la madre de Noguchi, al verlo casi manco, con una perspectiva de vida imposible para la labor de granjero o campesino, que era usualmente el único destino para un niño de su condición social, se abocó aún más devotamente a su cuidado y a su educación
(14). Como describen todos los biógrafos de Noguchi, la relación entre ambos fue muy profunda y estrecha (16). La laboriosidad, perseverancia y fuerza de voluntad parecen haber sido transmitidos al hijo a partir de la madre, quien era analfabeta pero aprendió a escribir, ya siendo anciana, para redactar las misivas de su puño y letra que llegarían hasta su hijo en Nueva York (14). Muchos años después, en el pináculo de la gloria, Noguchi proclamaría con énfasis: "Toda esta gloria y fama son nada, comparados con el amor que mi madre me entregó." (1).

$\mathrm{Su}$ instrucción escolar la recibió en la humilde escuela local, donde soportó burlas de sus compañeros por su defecto físico (su apodo era "mano de palo") (17) y se acostumbró a ocultar la extremidad deforme en la manga del kimono. Aunque empezó sus estudios a mayor edad que el resto de niños, y debía asumir trabajos de medio tiempo para compensar la magra economía familiar (carbonero y pescador, entre otros), su tenaz aplicación y su notable inteligencia lo hicieron sobresalir rápidamente (14). Un docente supervisor de escuelas rurales, Sakae Kobayashi, sorprendido ante las virtudes del prometedor jovenzuelo, lo tomó bajo su protección y le brindó apoyo material y espiritual para continuar sus estudios escolares secundarios, aunque para ello Seisaku debía caminar casi tres millas diarias y en medio de la nieve en los meses invernales (16). Kobayashi llegó a convertirse en padre espiritual por el resto de la vida de Noguchi (18). Es difícil imaginar las vivencias que experimentaba Noguchi, admirado por su inteligencia pero también tratado con rechazo por su deformidad física y sintiéndose hábil recipiendario del caudal de novedosa información y conocimientos que afluía al Japón, recién abierto a Occidente, a medida que iba creciendo y empezaba a ser un adolescente.

Gracias al apoyo de personas de buena voluntad fue sometido a varias intervenciones quirúrgicas para obtener el mayor grado de funcionalidad posible en su mano izquierda -experiencias trascendentes pues además sembraron en su ser la inquietud vocacional hacia la medicina- (14). La última y más decisiva intervención fue a sus 16 años de edad, a cargo de un cirujano que ejercería gran influencia en el futuro de Noguchi: Kanae Watanabe, recientemente llegado de su formación médica en California (EEUU) y prototipo del médico exitoso - de vestimenta y actitudes completamente occidentalizadas - quien ejercía como jefe en la Clínica Kaiyo, en Aizuwakamatsu (19). De hecho, al terminar su instrucción escolar en marzo de 1893, Noguchi pasó a dicho establecimiento como 
mandadero y aprendiz, y junto a sus lecturas médicas y experiencias al lado del facultativo, se dedicó con ahínco al aprendizaje de idiomas como inglés, francés, alemán y otros (20) -se cuenta incluso que se bautizó para practicar idiomas con los misioneros religiosos foráneos- (14). Otra experiencia crucial de este periodo fue el primer contacto de Hideyo Noguchi con el microscopio, que al parecer lo deslumbró (17).

Luego de tres años de intenso estudio y ayudantía médica, Noguchi grabó con una navaja en una columna de madera de su casa la frase: "Si no consigo mi objetivo, no volveré al hogar" y partió a Tokio (figura 3), la capital del imperio, a esas alturas ya la ciudad más poblada del mundo (17). Allí aprobó el primer examen de licenciamiento de la carrera médica (20). Como era lo usual, su escasez de recursos económicos lo obligó a trabajar y lo hizo en la clínica dental Chiwaki, donde sus alumnos se sorprendieron de que, quien al inicio era un humilde bedel de la casa, tras cursar algunos cursos obligatorios en la escuela médica de Saiseigakusha y aprobar la segunda parte del examen de licenciatura médica -logró en seis meses lo que a excelentes estudiantes les tomaba hasta tres años- (18) se convirtiera en su profesor. A la edad de 21 años, habiendo sido fundamentalmente un autodidacta, Noguchi poseía ya formalmente el título que lo autorizaba a ejercer como médico; sin embargo, su futuro era incierto: no solo carecía de recursos económicos sino que sus instructores temían la reacción de los pacientes ante su mano deforme, y que esto limitase su futuro como galeno (17).

Tras graduarse, uno de sus muchos trabajos fue redactar artículos para una revista de divulgación médica y hacer traducciones de capítulos y libros de idiomas extranjeros al japonés (14): al parecer allí se cimentó su interés por la bacteriología, que atravesaba su época de oro pues Pasteur y Koch, vivos aún, acababan de protagonizar sus resonantes epopeyas científicas. De inmediato, Noguchi postuló a un puesto en el recién inaugurado Instituto de Enfermedades Infecciosas del famoso médico bacteriólogo Shibasaburo Kitasato, quien recién había retornado de Alemania tras adiestrarse seis años a la vera de Koch, y había alcanzado fama al aislar e identificar el bacilo del tétanos y establecer los primordios de la sueroterapia (21). En aquella época, Noguchi participó también en los servicios sanitarios portuarios donde cumplían cuarentena los buques que arribaban al imperio e hizo sus primeros viajes fuera del Japón, en misiones para controlar brotes de peste bubónica en la península de Manchuria (Rusia) y en Newchwang (China) (19). La

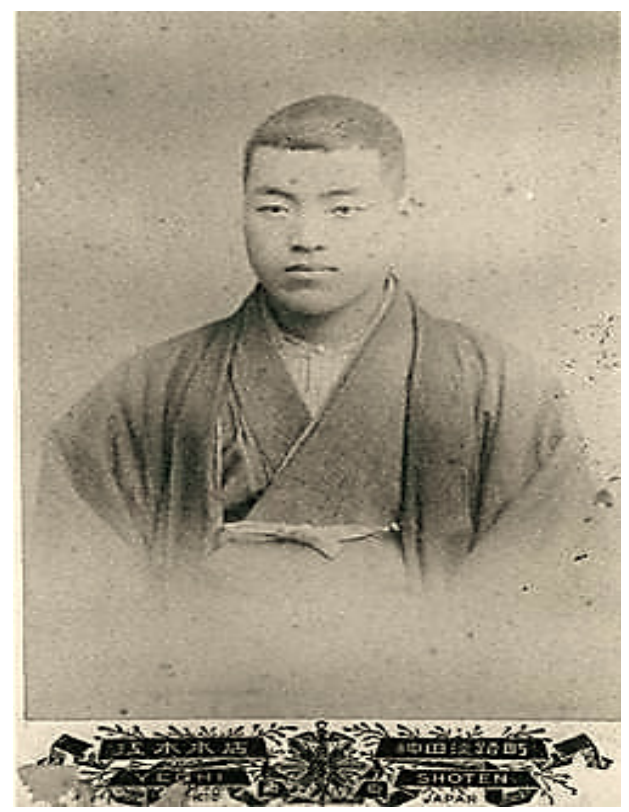

Figura 3. Seisaku Noguchi, antes de partir hacia Tokio (circa 1896), a poco de cumplir los 20 años de edad. (Fuente: https://www.cao.go.jp/noguchisho/english/ about/lifetimedrnoguchi.html)

lectura de la novela Tōsei Shosei Katagi (Retrato de un estudiante de hoy) de Tsubouchi Shōyō (1859-1935) donde el protagonista, un médico coincidentemente de nombre Seisaku Nonoguchi, frustraba su prometedora carrera sumiéndose en la depravación y el vicio, lo impresionó profundamente (14). Como Noguchi había tenido luego de su titulación múltiples episodios de expansión y francachela, en medio de sus usuales privaciones, -la leyenda afirma que aquí tuvo su primer contacto directo con la espiroqueta sifilítica y no precisamente en el laboratorio ni a través de un microscopio- (14), por superstición tal vez, y apelando a la costumbre nipona de cambiarse el nombre al llegar a la adultez, decidió reemplazar su nombre original, Seisaku, por Hideyo, que significa "gran hombre para el mundo" (20,21). Muy dentro de sí mismo, quizá se sentía ya un predestinado; estaba colmado de anhelos y de sueños.

Fue allí, en el Instituto Kitasato, que asomó la oportunidad que cambiaría su vida: una misión médica norteamericana visitaba Japón, rumbo a las Filipinas, donde el ejército yanqui mantenía tropas de ocupación; y fue obviamente inevitable escoger como cicerone de la delegación a Noguchi, por su condición políglota (15). Simon Flexner, autoridad médica en enfermedades infecciosas y futuro presidente de la Fundación Rockefeller, líder del grupo visitante, fue 
Primera centuria de la presencia de Hideyo Noguchi en el Perú.

abordado brevemente por Noguchi (16), quien le contó con ilusión su deseo de continuar en Norteamérica su incipiente carrera como médico e investigador, una ambición hasta ese momento sin tangibles esperanzas. Cortésmente y al desgaire, sin ofrecer mayores auspicios, Flexner replicó a su simpático guía nipón que desde luego, cuando se animase a viajar, él sería bienvenido por allá (22).

En ese sutil hilo cifraría Noguchi todo su futuro y en muy pocos meses atravesaría medio mundo, océano Pacífico de por medio, hasta llegar a la costa este de los Estados Unidos para empezar la nueva y asombrosa etapa de su vida.

\section{II. “The Human Dynamo” (Norteamérica, 1900-1915)}

Hideyo Noguchi era de talla baja: 5 pies y una pulgada (es decir, arañaba el 1,55 $\mathrm{m}$ de estatura), su contextura era menuda pero recia, y peinaba un prominente copete de su cabello negro sobre la frente, como para empinar su silueta (16). Su mirada era vivaz y despierta y todo el conjunto de sus movimientos revelaba energía plena y alerta (16). $\mathrm{Su}$ inglés era macarrónico (muy distinto es dominar el idioma para leer un texto médico que poder comunicarse con fluidez en un entorno extranjero) y sus modales orientales resultaban bastante peculiares en la sociedad neoyorquina de principios de siglo XX (22). Quienes lo conocieron, lo describen simple y sencillo como un niño, de característico buen humor, muy capaz de reírse de sí mismo, generoso, poseedor de encanto y simpatía cautivadores pero también extremadamente sensitivo, con tendencia a la soledad, muy reservado para sus asuntos personales, proclive a las fluctuaciones emocionales y a momentos de reclusión y de nostalgia $(16,17)$. Nada hacía prever que en pocos años, este diminuto súbdito japonés, aparentemente anodino, sería condecorado por reyes, recibido por dignatarios y estuviese a punto de ganar el Premio Nobel de Fisiología y Medicina, para el que recibiría hasta dieciocho nominaciones (23).

El 30 de diciembre del año 1900, con 24 años recién cumplidos, Hideyo Noguchi llegó a Philadelphia, en la costa este de EEUU, y se encaminó directamente hasta el domicilio de Simon Flexner, con el escaso dinero prestado que aún le restaba en los bolsillos (16). Luego de recibir los obsequios tradicionales japoneses llevados por su sorpresivo visitante, quien se deshacía en genuflexiones y sonrisas, el primer acto de Flexner fue comprarle un abrigo (24), pues Noguchi no había previsto la gélida temperatura invernal en el país del norte. Lo siguiente, dada la situación urgente, fue encontrar una posición laboral para él. Casualmente Silas Weir Mitchell, famoso galeno estudioso de diversos campos de la medicina -hoy se lo recuerda más como neurólogo-, estaba pronto a iniciar una investigación acerca de la inmunología de los venenos de serpiente (15). Flexner puso en contacto a Mitchell y al recién llegado y, aunque Noguchi reconoció que de venenos de ofidio sabía nada $-\mathrm{y}$ de métodos inmunológicos poco menos que nada- se entusiasmó y comprometió con la investigación al punto que, en el plazo de un año, y tras la consecución de varios auspicios privados, presentaron un amplio informe ante la Academia Nacional de Ciencias, y Noguchi publicó su primer artículo científico en los EEUU: Snake venom in relation to haemolysis, bacteriolysis, and toxicity (25). Este temprano logro permitió a Noguchi ser nombrado profesor asistente en la Universidad de Pennsylvania, a donde acababa de ser promocionado justamente Simon Flexner desde la Universidad Johns Hopkins (22), y quien a lo largo de toda la vida, como presidente de la Fundación Rockefeller para la Investigación Médica, y hasta después de la muerte de Noguchi, sería su principal benefactor y protector en tierras norteamericanas (17).

Si bien fue un azar afortunado que la carrera de Noguchi coincidiese con el periodo de auge temprano de la bacteriología e inmunología, no cabe duda de que sus dotes de extraordinaria laboriosidad, habilidad técnica, inteligencia analítica, entre otras virtudes, en cualquier momento hubieran garantizado por igual su precoz y fulgurante éxito (16). Otro hecho que llamaba la atención en él es que, pese a su deficiente expresión oral del inglés, su redacción de textos científicos era bastante correcta y casi no requería edición (14). Pero lo más llamativo era su ritmo de trabajo frenético, que le permitía dormir escasas horas cada noche, a veces de manera fraccionada, para saltar a sus implementos de laboratorio o a la redacción de sus artículos sin mayor transición ni pérdida de tiempo (15). Allí nació una leyenda que afirmaba que "Hideyo Noguchi no duerme" (26). Por su parte, Noguchi solía repetir una frase: "No existe la genialidad, pero si la hubiere, no sería otra cosa que trabajar tres, cuatro o cinco veces más fuerte que cualquiera." (14). Y vaya que dio cumplida prueba de eso: en breve tiempo Noguchi ganó una beca de la Fundación Carnegie para permanecer por un año en Copenhague, Dinamarca, a fin de perfeccionarse en inmunoquímica junto a Thorvald Madsen y Svante Arrhenius -quien ese año ganaría el Nobel de Química- (20). Había una chocante desproporción entre la fragilidad aparente 
de su complexión corporal y la dinámica energía que lo caracterizaba e impulsaba su pasión por la ciencia (16). Sus colegas y pares, que al inicio lo llamaban "la amenaza amarilla" -por su raza-, con admiración y cierta envidia empezaron a denominarlo "el dínamo humano" (27).

A su regreso de Dinamarca fue incorporado en la recién constituida Fundación Rockefeller para la Investigación Médica, donde permanecería por el resto de su vida (22). Sus ingresos anuales ascendían a 1800 dólares anuales de esa época (equivalentes al cambio actual a aproximadamente 52500 dólares al año) (14). Al poco tiempo, en 1905, llegó desde Alemania la resonante noticia de que F. Schaudinn había conseguido aislar la espiroqueta causante de la sífilis y se encargó a Noguchi dedicarse a ella, al Treponema pallidum, y en un par de meses él fue capaz de replicar los hallazgos de Schaudinn, siendo el primer científico de los EEUU en lograrlo $(17,22)$. Así se inició un periodo de intensa dedicación al tema que lo llevaría a la más notable conquista de la neuropsiquiatría norteamericana en los inicios del siglo XX: la demostración de la etiología bacteriana de la parálisis general progresiva (PGP) (28).

El común de psiquiatras hoy en día no ha visto ningún caso de parálisis general progresiva en su práctica, pero hasta mediados del siglo XX, la tercera parte de camas de los hospitales psiquiátricos era ocupada por pacientes con esta enfermedad cruel, que los afectaba tanto en lo neurológico como en lo psiquiátrico, con parálisis, psicosis y demencia (28). La sífilis probablemente haya tenido un efecto más profundo en el desarrollo de la psiquiatría, como disciplina médica, que cualquier otra enfermedad. (29) El hallazgo de la espiroqueta en el tejido cerebral significó romper un paradigma imperante mucho tiempo acerca de la dualidad mente-cerebro en cuanto a la etiología de la enfermedad psiquiátrica (29). Si bien se sospechaba que la sífilis estaba relacionada con la PGP, la identificación del Treponema pallidum y la demostración de su presencia en tejido cerebral, consolidaron este hito en la neuropsiquiatría y en el cambio de paradigmas neurocientíficos pues con el hallazgo de una causa infecciosa: juna enfermedad mental por primera vez se volvía potencialmente tratable!

Noguchi se empapó tan vorazmente en el tema de las espiroquetas y la sífilis que escribió un libro (Serum diagnosis of Syphilis) -que alcanzó varias ediciones- (30) sobre el diagnóstico serológico de esta infección, en base a su modificación de la prueba de Wassermann de fijación del complemento destinada a tal fin, y lo redactó a la supersónica velocidad de un capítulo por noche, enervado por enormes tazones de té y cigarros de tabaco negro (14). El siguiente paso de su cometido fue conseguir el cultivo in vitro del Treponema pallidum, bacteria muy exigente y delicada pero Noguchi lo logró -aunque en los años sucesivos esto sería motivo de interminable controversia y polémica - ensayando en cientos de tubos de ensayo -cuando lo usual eran solo decenas de ellos-y domesticando en primer término otros treponemas: aquellos que eran causantes de la frambesia y la pinta $(17,18)$. Y el asalto final de su conquista científica, luego de producir la infección sifilítica en primates con sus espiroquetas aisladas y cultivadas in vitro, fue el examen de setenta especímenes de cerebros y médulas espinales necropsiadas a partir de personas fallecidas con PGP, mediante centenares de cortes histológicos teñidos con tinciones argirófilas, noche tras noche, micrómetro a micrómetro, hurgando en todas las capas del córtex y la médula (31). Hasta que su esfuerzo tuvo fruto: donde muchos notables histólogos habían fallado, Noguchi triunfó. Su hallazgo fue publicado en el primer número del año del Journal of Experimental Medicine (31). Se iniciaba 1913.

Inmediatamente su triunfo resonó en el mundo. Fue invitado a congresos europeos, en Viena, en París, en Frankfurt, Estocolmo, Copenhague, Londres, a lo largo de ese año (14), para presentar sus sorprendentes hallazgos y fue aclamado y premiado - además de codearse con eminencias de la talla de Paul Ehrlich e Iliá Méchnikov, quienes fueron impresionados por el carisma del exótico investigador nipón- a la vez que las primeras nominaciones de su persona al premio Nobel se fueron suscitando $(22,23)$. El año 1914 trajo para Noguchi su consolidación plena dentro del Instituto Rockefeller al ser nombrado miembro asociado, el más alto nivel de importancia en el escalafón de los investigadores científicos de la institución (18) (figura 4).

En el ínterin de su vida personal, Hideyo Noguchi había contraído matrimonio. Mary "Maizie" Loretta Dardis, ciudadana americana, hija de inmigrantes irlandeses, a la que había conocido años antes en un evento social, nacida en Scranton, Pennsylvania, en el mismo año que él, aceptó ser su compañera de vida y hasta la muerte (20). Las nupcias, acontecidas en 1911 (¿1912?), se mantuvieron en secreto durante largo tiempo por el temor de Noguchi de que se afectase su expectante posición en el Instituto Rockefeller 


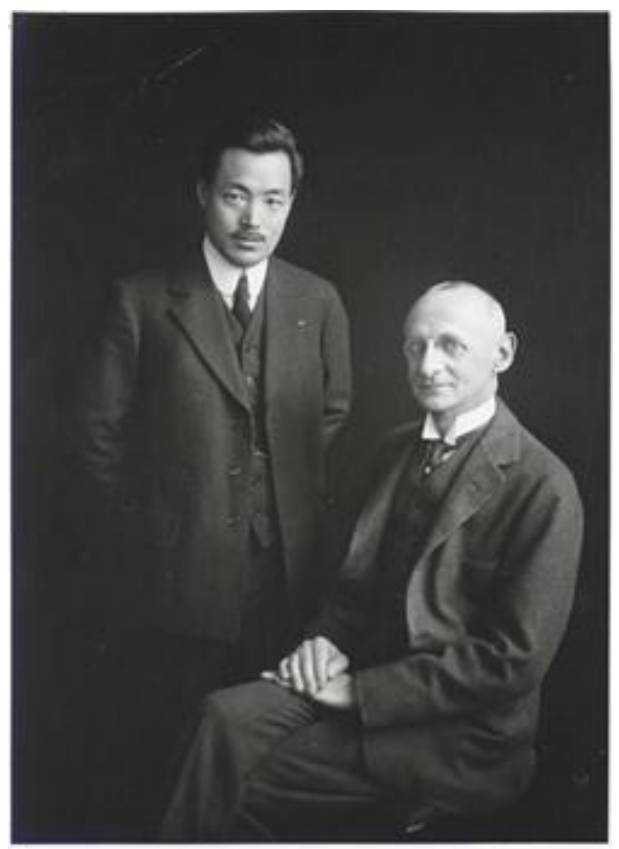

Figura 4. Hideyo Noguchi y el Presidente de la Fundación Rockefeller, Dr. Simon Flexner (1914) cuando Noguchi fue nombrado miembro pleno del Instituto Rockefeller. (Fuente: https://www.cao.go.jp/noguchisho/english/ about/lifetimedrnoguchi.html)

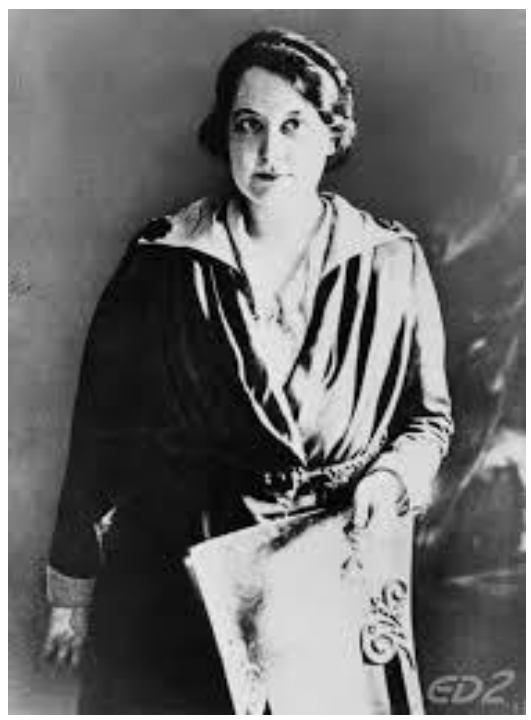

Figura 5. Mary "Maizie" Loretta Dardis (1876-1947), esposa de Hideyo Noguchi. (Fuente: https://ameblo.jp/ fumiakityan/entry-12001253768.html)

$(14,32)$.Y aunque cuando sorprendían a Noguchi en altas horas de la noche en el laboratorio y le inquirían ¿porque no estaba en su hogar?, su réplica usual fuese: "¿Hogar? Este es mi hogar" (16), ello no pasaba de un travieso postureo, pues las cartas de ambos, conservadas hasta la actualidad, revelan cómo desde cualquier lugar del mundo donde estuviese Hideyo (ella lo llamaba "Hidey"), Maizie representaba un íntimo baluarte de apoyo y refugio cálido siempre, en el sentido más familiar y amoroso de los términos (Figura 5) (3). Ya viuda, Maizie lo sobreviviría 19 años. El matrimonio no llegó a tener hijos (16).

Luego de su triunfal periplo europeo, Noguchi retornó a Japón a finales del año 1915, tras quince años de ausencia, también en aroma a triunfo y gloria: aparte de la bienvenida de la gente que lo aclamaba, fue distinguido con doctorados y laureles imperiales $(19,21)$. El reencuentro con sus antiguos protectores, profesores y amigos (su padre espiritual Sakae Kobayashi; el Dr. Kanae Watanabe, de la Clínica Kaiyo; y el odontólogo Morinosuke Chiwaki), con quienes nunca suspendió contacto epistolar, fue efusivo (20). Pero más lo fue el abrazar otra vez a su madre Shika, ahora inevitablemente achacosa y envejecida (Figura 6) (14). Pese al tráfago de ceremonias y saraos oficiales durante los dos meses de su visita, Noguchi dispuso de unos días para departir a solas con su madre y su padre espiritual $(14,21)$, en la vieja casa de Sanjogata, en una de cuyas columnas dejó escrita una promesa juvenil, y que había sobradamente cumplido.

\section{NOGUCHI Y EL PERÚ}

Los vínculos de Hideyo Noguchi con nuestro país, durante su breve vida, acontecieron de dos modos: en primer término con su presencia física durante alrededor de un mes en el año de 1920, patrocinado por la Fundación Rockefeller en viaje de investigación ante una epidemia de fiebre amarilla. Y por otra parte, con el esclarecimiento definitivo y consolidación de la teoría unitaria acerca de la fiebre de la Oroya y la verruga peruana, cuya identidad nosológica como dos facetas de un mismo proceso patológico Noguchi estableció plenamente, mediante prolongados trabajos de laboratorio y múltiples publicaciones suyas a propósito, en los Estados Unidos (11).

Desde el siglo XVII hasta los principios del siglo pasado, la fiebre amarilla fue considerada como una de las mayores plagas de América y del África (33). Ciudades tropicales y subtropicales, sobre todo portuarias, eran vulnerables a brotes epidémicos que diezmaban y aterrorizaban a la población y afectaban las actividades productivas. Entre 1919 y 1922 se desarrolló en el norte del Perú (Tumbes y Piura) un brote epidémico de fiebre amarilla (11). Aunque 


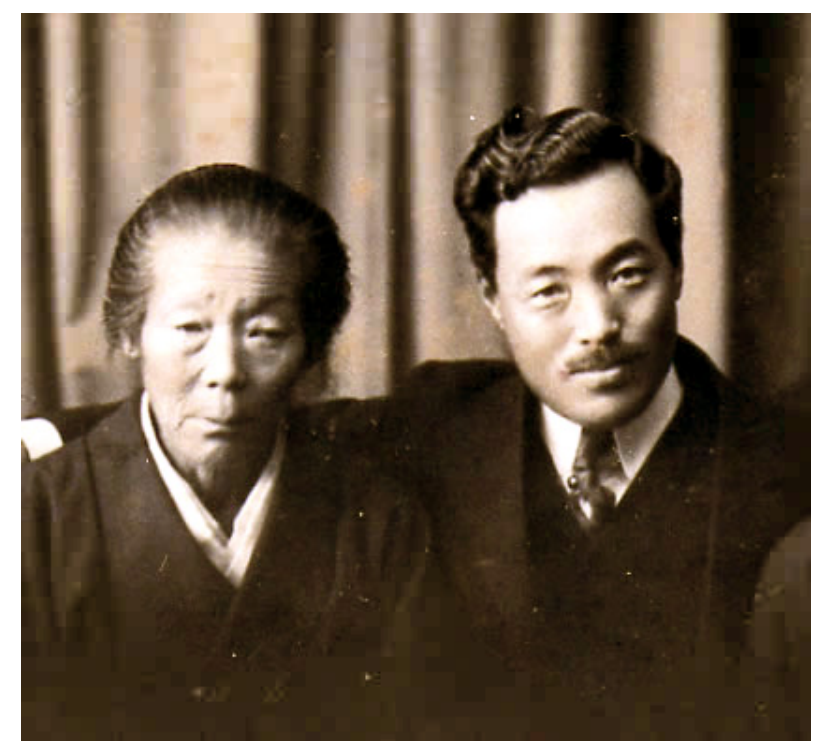

Figura 6. La famosa $-y$ única- fotografía de Noguchi con su madre, Shika, durante el viaje a Japón de 1915. Tres años después, a los 65, ella falleció. (Fuente: https://upload.wikimedia.org/wikipedia/commons/b/bc/ Noguchi_Hideyo.png)

William Gorgas, médico militar norteamericano había librado a La Habana y también a la zona del Canal de Panamá de esta plaga, entre 1902 y 1906, mediante la erradicación del insecto vector Aedes aegypti -y permitiendo así la construcción de dicha magna obra de ingeniería-, aún no se conocía al agente etiológico de la enfermedad, por lo que no se podían elaborar vacunas ni sueros antiamarílicos (33). La Junta Internacional de Sanidad de la Fundación Rockefeller decidió esclarecer los puntos oscuros subsistentes acerca de esta enfermedad y envió a Noguchi, quien empezó su periplo americano en Guayaquil en 1918, puerto ecuatoriano que era desde hace mucho tiempo un foco endémico (22). Aunque se logró sofocar el brote y se levantó la cuarentena de casi un siglo sobre el puerto, el hecho más sonado de la misión fue que Noguchi afirmó haber aislado el germen de la fiebre amarilla, casualmente otra espiroqueta, a la que denominó Leptospira icteroides (34). Noguchi fue instituido como coronel honorario del ejército de ese país y colmado de honores (20).

El 5 de mayo de 1920 Hideyo Noguchi llegó directamente a Paita, puerto del norte peruano, por vía marítima (11); lamentablemente cuando arribó los casos de fiebre amarilla habían disminuido ostensiblemente, así que tuvo que trabajar con los pacientes que le fueron presentados como "casos recientes de fiebre amarilla", pero sin tener real certeza del diagnóstico
(35). Vale la pena citar fragmentos del artículo original de Noguchi (36) para juzgar la situación de la realidad peruana en ese entonces -la traducción es nuestra-: "Paita, un pueblo de 3000 habitantes, es el principal puerto del norte del Perú. Consiste en un puñado de chozas de caña sobre una franja de tierra arenosa pegada al mar. El agua tiene que ser traída desde siete kilómetros de distancia y usualmente es insuficiente para las necesidades de la población. (...) No había alimento para los conejillos de Indias experimentales por lo que $2 / 3$ de ellos fallecieron. (...) Debido a la falta de fluido eléctrico, no se pudo emplear el microscopio de campo oscuro, esencial para la observación de espiroquetas. (...) No era posible hacer la coloración de Giemsa por la pésima calidad del agua. (...) Era difícil que los pacientes acepten dar una muestra de sangre, y dar una segunda muestra siempre fue imposible.” Dadas las dificultades, la investigación y el equipo (formado por Noguchi y su asistente J.Kligler) se trasladaron a Piura aunque también visitaron brevemente Morropón. Antes de partir a Lima el 26 de mayo, fueron despedidos en una cena de gala con menú francés de más de 10 platos, lo que sorprendió a los extranjeros dada la enorme pobreza del lugar (11). Javier Mariátegui especula con la posibilidad de que Honorio Delgado e Hideyo Noguchi pudiesen haberse cruzado en Piura (8), pues Delgado viajó también en misión contra la epidemia de fiebre amarilla pero es poco probable pues, cuando Noguchi llegó, la epidemia ya prácticamente había desaparecido. Por añadidura, Honorio Delgado, en sus diversos escritos sobre Wagner Jauregg y la malarioterapia curativa de la PGP, consecuencia directa del hallazgo de Noguchi, no habría podido dejar de mencionar haberlo conocido o siquiera entrevisto en tierra peruana.

Luego de tres días de viaje en el vapor Ucayali, Noguchi llegó a Lima y se instaló en el Hotel Maury, el más lujoso de la época (el Bolívar se concluiría para el siguiente año: centenario de la Independencia) (11). Acudió a presentar su saludo al Presidente Augusto B. Leguía, quien le propuso contratarlo para fundar y presidir un instituto de investigación biomédica en el Perú, oferta que comprensiblemente Noguchi declinó, y visitó además los hospitales Dos de Mayo y Santa Ana. La tarde del 2 de junio pronunció una conferencia magistral sobre la fiebre amarilla, en el Paraninfo de la Facultad de Medicina de San Fernando, y recibió el título de Profesor Honorario del claustro sanmarquino (11). Si bien reconoció que las principales armas preventivas contra la fiebre amarilla eran la erradicación del mosquito vector y el saneamiento ambiental, exaltó su hallazgo de Leptospira icteroides como agente 
Primera centuria de la presencia de Hideyo Noguchi en el Perú.

causal y defendió la vacuna y sueros por él preparados. En estancias posteriores en Yucatán (México), Cuba y Brasil (37), Noguchi siguió apuntalando su hallazgo de L.icteroides como causante de la fiebre amarilla y núcleo de toda su teoría fisiopatológica y terapéutica al respecto (35).

Durante su estancia en el Perú fue entrevistado por varios medios de comunicación escritos de la época (11). Incluso una delegación de japoneses emigrados al Perú fue a visitarlo (la migración japonesa tenía aún poco tiempo en nuestro país) y le expresaron quejas por percibir sentimientos de exclusión y racismo en la sociedad peruana. Noguchi sonrió y señalando su cabeza declaró: "El problema está aquí. Uds. deben estudiar más. Aprovechen mientras están jóvenes, sueñen en grande y esfuércense para lograr una meta. A mí me tratan como si fuera una deidad donde quiera que voy." (11).

Antes de su partida desde el puerto de El Callao a los EEUU, el 5 de junio de 1920, tomó nota de la polémica aun subsistente en torno a la enfermedad de Carrión: si la fiebre de la Oroya y la verruga peruana eran o no facetas de una misma patología -o eran dos entidades nosológicas totalmente diferentes- e incorporó decididamente este tema de investigación a su agenda pendiente en el Instituto Rockefeller (38): aunque prometió volver al Perú para desarrollar tales investigaciones, la imposibilidad de dicho desplazamiento físico no excluyó que el Perú viajase en la mente de Noguchi como memoria latente y firme compromiso, y desde la distancia Noguchi cumpliese cabalmente con la memoria de Carrión -es muy factible que él se haya identificado íntimamente con la imagen de aquel estudiante humilde y de vocación científica denodada, que murió mártir de la cienciay con el Perú.

La autoinoculación de Carrión en 1885, con líquido extraído de una verruga de un paciente afectado y el desarrollo de la fiebre anémica que lo llevó a la muerte, ya había dado una pauta de la identidad de ambas patologías (39). De hecho, esto se venía sospechando desde antes de su martirologio: la coincidencia estrecha de zonas geográficas afectadas por ambas patologías, por ejemplo, y una serie de observaciones clínicas habían orientado correctamente en ese sentido. Faltaba la confirmación bacteriológica y allí tuvieron papel crucial desde 1901 las observaciones de Alberto Barton, médico de ascendencia inglesa y que había nacido en Argentina pero que radicó toda su vida en el Perú, aunque en muchas épocas fue soslayado por los círculos médicos oficiales (40). Su tesis de bachiller "El germen patógeno de la enfermedad de Carrión", sustentada el 5 de octubre del año 1900, describe al microorganismo como "un bacilo protoplasmático bastante móvil, de aspecto corto y grueso y de extremidades redondeadas, ávido de oxígeno, fácilmente coloreable con anilina y cultivable en caldo y gelatina". En experiencias posteriores fue delineando mejor sus hallazgos, corrigiendo sus errores, y aunque hubo diversa y continuada oposición a sus descubrimientos - no siempre con preeminencia de argumentos estrictamente científicosprogresivamente se fue consolidando la perspectiva de que Barton había efectivamente descubierto el germen de la fiebre de la Oroya y se reconoció ello bautizando al bacilo como Bartonella bacilliformis $(33,38)$. La comisión presidida por Richard Strong, de la Universidad de Harvard, que visitó el Perú en 1913, reconoció que la B.bacilliformis era una bacteria, no un detrito intracelular, y que efectivamente era la causa de la fiebre de la Oroya pero... reiteró el error de diferenciar a la fiebre de Oroya como una patología distinta y ajena a la verruga peruana, suponiendo para la verruga un germen infeccioso aún no hallado (40). Como Strong tenía el prestigio de lo extranjero (y los peruanos solemos sobrevalorar eso) para cuando Noguchi estuvo en Perú en 1920, aún persistía la duda al respecto: ¿se trataba de una sola o de dos enfermedades?

En 1925, un discípulo de Barton, Telémaco Battistini, médico peruano de origen italiano, reportó haber replicado detenidamente los hallazgos de Barton $(38,40)$, esta vez logrando el cultivo puro y el aislamiento de cepas, y luego procediendo a inocularlas pudo reproducir la enfermedad en ambas expresiones (fiebre de la Oroya y verruga peruana), en experiencias que venía desenvolviendo desde el año 1920. B.bacilliformis era de cultivo difícil, reconoció, aunque no llegó a enviar sus hallazgos a revistas extranjeras para lograr el justo y necesario reconocimiento (40). Gracias a una beca pudo viajar a los Estados Unidos como fellow del Instituto Rockefeller y Battistini fue coautor, en 1926, de la primera publicación que Hideyo Noguchi consagró al tema (41) de un total de más de 20 artículos sucesivos (11). Posteriormente Noguchi, con muestras de verrugas remitidas desde el Perú, reprodujo en monos Macacus rhesus una forma idéntica a la fiebre de la Oroya, por lo que consideró legítimo y así lo señaló explícitamente, que la enfermedad debía llevar el epónimo de enfermedad de Carrión (42) -se afirma que Noguchi se sintió feliz de dar la razón al olvidado 
estudiante de medicina Daniel A. Carrión por encima de la comisión de la Universidad de Harvard- (15). Cerró con broche de oro la serie de estudios sobre la enfermedad de Carrión, demostrando elegantemente junto con R.C. Shannon, entomólogo, que era un pequeño mosquito endémico en las zonas afectadas llamado "titira" (Lutzomya verrucarum) -en un inicio el género se denominó Phlebotomus -, el vector transmisor de la enfermedad. Estos últimos estudios llegaron a ser publicados póstumamente $(43,44)$, pero fueron redactados cuando nada hacía prever el desenlace fatal de Noguchi. El compromiso de Noguchi con el Perú y con la resolución del misterio persistente de la emblemática enfermedad de Carrión, empeñado ocho años antes para lograr su plena clarificación bacteriológica, aún en medio del tráfago de sus múltiples investigaciones y viajes, había sido satisfactoriamente cumplido.

\section{OCASO Y AGONÍA (1918-1928)}

¿Qué factores determinaron que un científico como Noguchi, que llegó a los más altos niveles de acreditación científica y nombradía, fracasase finalmente en diversos proyectos de investigación de modo resonante y sin atenuantes? Recordemos y tengamos en cuenta algunos hechos básicos: aunque la revisión por pares (peer review) tiene una venerable historia que se remonta a 1731 y a las publicaciones de la Royal Society of Edinburgh; tardó mucho tiempo en generalizarse y establecerse como una práctica regular. Las publicaciones científicas en la época de Noguchi a lo más eran sometidas a una somera lectura por el editor de la respectiva revista, no eran revisadas por expertos independientes y acreditados, lo que recién se hizo práctica firme a partir de los años posteriores a la Segunda Guerra Mundial (45). En el caso de Noguchi, la revista donde publicó la inmensa mayoría de sus trabajos era el Journal of Experimental Medicine, revista oficial de la Fundación Rockefeller, y cuyo editor jefe era precisamente Simon Flexner, su incondicional amigo y benefactor.

Otro dato característico de Noguchi, y que influiría en la nula revisión de los resultados que llegaba a publicar, datos que ningún otro investigador más podía replicar ni corroborar posteriormente, era su rechazo a compartir coautorías en sus trabajos (46), él quería "todo o nada" (15) (rezago tal vez de su condición de único hijo varón, idolatrado por la madre). En algunas de sus comunicaciones epistolares él mismo lo reconocería así (47). Y aunque las autorías masivas de grandes proyectos de investigación (decenas de autores para una sola publicación) son relativamente recientes pues los estudios policolaborativos y multicéntricos son de rigor hoy en día, el empecinamiento de Noguchi de trabajar solo, redactar sus trabajos solo y no ser revisado ni supervisado por algunos de sus pares, impidió que se percatase a tiempo de posibles errores por omisión o comisión, así como le privó de una perspectiva crítica y zahorí para ir perfilando sus trabajos de investigación científica. Noguchi efectuaba hasta las propias ilustraciones de sus artículos (acuarelas usualmente, en lo cual era superlativamente bueno, al punto que se decía que cualquier tarea que se propusiese hacer, la haría bien) $(17,18)$, cosa que al parecer él creyó al $100 \%$.

A lo largo de su vida, Noguchi tuvo la costumbre inveterada de abordar a la vez varios temas de investigación: no aspectos de un mismo tema sino varios temas, a veces totalmente diferentes (15), al punto que uno de sus biógrafos exclamó que lo sorprendente no era el número de temas de investigación acometidos, sino que de tantos hubiese habido éxito en al menos algunos (16). Un resumen de los artículos publicados por Noguchi según el tópico, nos permite ver esta dispersión -21 artículos sobre venenos de serpiente, 12 sobre anticuerpos, 21 sobre complemento, 31 sobre espiroquetas, 27 sobre sífilis y diagnóstico serológico, 9 sobre T.pallidum y PGP, 7 sobre tracoma, 6 sobre poliomielitis, 4 sobre rabia, 20 sobre fiebre de la Oroya, 34 sobre fiebre amarilla, y un largo etc., (15)-. Esto, sumado a su costumbre peculiar de no empaparse a fondo de la bibliografía previa "para no dejarse influir negativamente con los errores de otros", lo expuso precisamente a cometer o no detectar errores (15). Si a eso se añade lo que más de un investigador visitante observó en su laboratorio: un peculiarísimo "orden", con montones de tubos a diestra y siniestra, carentes de cualquier etiqueta identificatoria -aunque Noguchi afirmaba saber exactamente de qué se trataba cada vial- (17), debemos concluir que una mezcla de confianza ciega en sí mismo, desprolijidad técnica, sobrecarga autoimpuesta y prácticas de laboratorio poco ortodoxas, fueron arrojando una suma de errores acumulativos de los que Noguchi no pudo salir por sí mismo. Dios ciega a los que quiere perder.

Así fue el caso del tracoma: una queratoconjuntivitis crónica que es la principal causa infecciosa de ceguera en el mundo y afecta sobre todo a la población más desfavorecida (48); se supone que la hermana mayor de Noguchi, Inu, padeció esta forma de ceguera, lo que le habría motivado a estudiar el tracoma desde fechas tan tempranas como 1905 (14). La sospecha del 
Primera centuria de la presencia de Hideyo Noguchi en el Perú.

tracoma como enfermedad infectocontagiosa ya existía desde el siglo XIX, pero la dificultad de identificar un microorganismo causal hacía intuir un posible virus o patógeno similar. Noguchi aisló un supuesto Bacterium granulosis de la secreción ocular de un enfermo de tracoma, la aplicó a los ojos de varios monos, en los que apareció una conjuntivitis folicular e hizo cultivos adicionales (49). En 1927, Noguchi presentó estos hallazgos a la Asociación Médica Americana y algún oftalmólogo se infectó un ojo con dicha bacteria solo para demostrar que se trataba de un germen saprofito inocuo -lo que efectivamente era- (15). Finalmente se demostraría que el germen detectado por Noguchi era anodino y el germen causal del tracoma se trataba de una bacteria intracelular: Chlamydia trachomatis (49).

Sus estudios respecto a la poliomielitis resultaron también frustros: Noguchi sospechaba de una especie de protozoo que formaba "cuerpos globoides" (15) y produjo una serie de estudios no siempre factibles de ser reproducidos. Recuérdese que no sería sino hasta la década de 1930, con el desarrollo del microscopio electrónico por Ernst Ruska, que se logró definir con claridad muchos ámbitos de la investigación virológica (35). Si los procedimientos y técnicas de laboratorio de 1913 hubiesen estado más avanzados, probablemente Noguchi habría logrado confirmar que el poliovirus no estaba restringido al tejido nervioso y que él había logrado cultivarlo en tejido renal, pero se había adelantado a su tiempo (14). Sus intentos de cultivar el virus de la rabia también resultaron fallidos (22).

Otro aspecto polémico y controversial en que se halló envuelto Noguchi fue el escándalo de la "luetina" y su aplicación sin consentimiento informado: la luetina era un extracto de moléculas del T. pallidum -recientemente identificado agente causal de la sífilis-, sometido a temperaturas elevadas y desnaturalización con fenol, sin ninguna propiedad infecciosa y que inyectada por vía subdérmica debía originar una reacción de hipersensibilidad localizada (50), y que sería útil para el diagnóstico de la sífilis análogo a la tuberculina de von Pirquet-. La luetina ofrecía ventajas supuestamente respecto a la prueba de Wassermann, que en sujetos con sífilis terciaria muchas veces resultaba negativa (16). Noguchi aplicó experimentalmente su luetina a una muestra de 400 personas: 254 de ellas pacientes con sífilis establecida y procedentes de hospitales y asilos neoyorquinos, y los otros 146 eran personas "control", sanos -como niños de un orfanato- o con otros padecimientos. Hubo un escándalo y una denuncia contra Noguchi propiciada por la Sociedad Antiviviseccionista de Nueva York -mantenía el nombre de "antiviviseccionista" pues su propósito fundador fue la oposición contra la experimentación en animales- (51). Debemos precisar que en esa época no existía aún el concepto ético de consentimiento informado tal como lo conocemos hoy en día (18). La defensa de Noguchi se articuló alrededor de la seguridad del procedimiento y la utilidad del test (51). De hecho, Noguchi y un conjunto de colaboradores de la Fundación Rockefeller, luego de la experimentación en animales de ensayo, se habían aplicado la luetina a sí mismos previamente. Según apunta un biógrafo de Noguchi, este no habría expuesto tal punto en el reporte por su propia condición oculta de sifilítico (15). Como resulta obvio, la conducta de Noguchi al usar un agente no infeccioso, probado antes en sí mismo, estuvo lejos de egregias violaciones de la ética biomédica como los infaustos experimentos con sífilis de Tuskegee (19321972) (18); pero el incidente marcó el alejamiento de Noguchi de las investigaciones sobre la sífilis... aunque no de las espiroquetas.

El definitivo y más resonante fracaso de Noguchi, el golpe final y con el que literalmente acabó perdiendo la vida, fue el relacionado a sus investigaciones sobre el agente etiológico de la fiebre amarilla, a las que consagró los últimos diez años de su existencia (52). Casualmente, en 1915 se había diagnosticado a Noguchi una hipertrofia cardiaca junto a una insuficiencia aórtica clínicamente sintomática -casi seguramente de etiología sifilítica-, lo que aconsejaba apaciguar su incansable ritmo de vida, a la vez que disminuir su excesivo tabaquismo (14). Sin embargo, como recordamos, desde 1918 Noguchi había emprendido una serie de prolongados viajes por diferentes lugares de Latinoamérica, empezando en el puerto de Guayaquil, desde donde preconizó su hallazgo de una espiroqueta, a la que bautizó como Leptospira icteroides (por la ictericia característica de la enfermedad), como el microorganismo causal incuestionable de la fiebre amarilla: rubricó sus observaciones en México (Yucatán), Perú (Piura), Cuba y Brasil (37); elaboró sueros de efecto supuestamente neutralizante de la fiebre amarilla y hasta una vacuna ad hoc, todo lo que se distribuyó mundialmente a través de la buena propaganda del Instituto Rockefeller (47).

Justamente, duramente su viaje a Japón en 1915, Noguchi había tenido conocimiento del hallazgo de Inada e Ido, dos microbiólogos japoneses, acerca del 
agente causal de la enfermedad de Weil o leptospirosis: Leptospira icterohemorragica (53). Esta patología producía síntomas muy semejantes a los de la fiebre amarilla -ictericia, fiebre, polimialgias, inyección conjuntival, diátesis hemorrágica y albuminuriaal punto que muchas veces resultaba imposible distinguir una enfermedad de otra a partir de los datos clínicos (35). Obviamente había diferentes reservorios y mecanismos de transmisión divergentes entre una enfermedad y otra. Noguchi, que tenía una amplia experiencia en espiroquetas, creyó identificar rápidamente, a pocos días de su llegada a Guayaquil, a su enemigo en forma de una espiroqueta también (47).

Los estudiosos de la obra de Noguchi han señalado muy claramente el hecho de que, como es obvio, un microbiólogo que estudia el putativo germen de una enfermedad, dependerá de la calidad de los diagnósticos de los pacientes puestos a su disposición, en cuanto estos diagnósticos sean homogéneos y confiables y representen exactamente la patología que se pretende estudiar (35). En ese sentido, dos errores capitales en los que incurrió Noguchi fueron: primero, actuó de buena fe recibiendo como "casos" todos los que le proporcionaban los médicos locales, aunque muchos de ellos probablemente no eran casos de fiebre amarilla, sino de leptospirosis, o de ambas patologías (pues las zonas endémicas para ambas eran similares) y sin intentar un diagnóstico diferencial mínimo (35). El segundo: "olvidó" el postulado de la comisión presidida por Walter Reed que había investigado la fiebre amarilla a principios de siglo: que el agente infeccioso habría de ser ultrafiltrable y de naturaleza no bacteriana, además de que el uso de voluntarios humanos sería imprescindible en cuanto los animales de experimentación usuales no contraían naturalmente la enfermedad. (47) El uso de conejillos de Indias facilitó el autoengaño de Noguchi, pues estos animales son susceptibles a la leptospirosis pero no a la fiebre amarilla (47). Cuando la misión de la Fundación Rockefeller viajó a África en 1925 y empezó a evaluar casos y más casos de fiebre amarilla sin hallar en ninguno de ellos la L.icteroides, la teoría y hallazgos de Noguchi empezaron a tambalear. De hecho, ese mismo año tales postulados habían sido abiertamente cuestionados en la Conferencia Mundial de Medicina Tropical que se había llevado a cabo en Kingston, Jamaica (52): nadie en todos esos años había podido distinguir la Leptospira icterohemorragica, causante de la leptospirosis o enfermedad de Weil, de la L.icteroides, que solo Noguchi parecía ser capaz de poder caracterizar y aislar.
Dada la acuciante situación, Noguchi mismo exigió viajar a África (47). Todo su honor científico se hallaba gravemente en cuestionamiento. Llegó hasta allá el 17 de noviembre de 1927, y estableció su centro de operaciones en Accra, en la costa de la actual Ghana, entonces colonia británica (16). Se había observado que los monos de la especie Rhesus, traídos desde la India, sí eran susceptibles a la infección experimental por fiebre amarilla y se consiguieron centenares de ellos en inmensas jaulas para aprovisionar los bioterios de Noguchi, quien como hipótesis salvadora de investigación había planteado la posibilidad de existencia de "dos fiebres amarillas": una americana, donde el agente causal sería su famosa e inasible Leptospira icteroides, y la africana, cuyo agente supuestamente sería diferente y aún desconocido (47). A lo largo de sus experimentos, usualmente llevados a cabo a solas y en altas horas de la noche, sus hallazgos parecen haber sido contradictorios, al menos una versión era la que brindaba en sus cartas a Flexner, su jefe y protector en los EEUU, y otra la que divulgaba a los diversos miembros de la expedición. Incluso eran evidentes sus descuidos respecto a las medidas de bioseguridad en el laboratorio, en cuanto a que las cajas donde se mantenían mosquitos infectados para la transmisión del agente patógeno no se manipulaban con las debidas precauciones (52). Al parecer, Noguchi se hallaba completamente convencido de ser inmune a un posible contagio. $(47,52)$ Lamentablemente, para comienzos de enero de 1928, Noguchi había contraído la fiebre amarilla.

Tuvo suerte, al menos en ese momento. Hubo una progresiva y espontanea mejoría que él atribuyó a estar inmunizado con la vacuna de su propia elaboración (47). En cuanto entró en convalecencia acometió nuevamente de manera denodada sus experimentos: tenía listo el material de doscientas autopsias de monos y centenas de tubos de cultivos y frotis preservados y embalados para ser remitidos a los EEUU, antes de su partida fijada para fines de mayo (14). Allá planeaba finiquitar sus experiencias y dar por resuelto el misterio de las dos fiebres amarillas, aunque los que estaban a su alrededor lo notaban fácilmente irritable, insatisfecho, receloso, como si el verdadero estado de sus investigaciones lo tuviese abrumado por dentro (47). En un último periplo a Lagos, en Nigeria, a mediados de mayo de 1928, solo para despedirse del resto del equipo investigador pues ya estaba listo su retorno a Nueva York, se le declaró nuevamente la enfermedad (52). Con su propia sangre se llegó a infectar a dos macacos Rhesus, quienes en pocos días fallecieron y sus hallazgos de necropsia 
fueron inequívocos: el contenido estomacal de vómito negro, la afectación hepática hemorrágica, el insidioso daño renal, demostraban ser casos incuestionables de fiebre amarilla (15).

Hideyo Noguchi falleció el 21 de mayo de 1928, a los 51 años de edad, tras prolongados días de agonía en el hospital de Accra (47); los resultados de su autopsia confirmaron el diagnóstico de fiebre amarilla como causa de su muerte (52). Todo su laboratorio y efectos personales fueron incinerados como medida de salud pública. Todos los cultivos que remitió a los EEUU resultaron negativos para Leptospira icteroides o cualquier otra bacteria. Sus restos mortales llegaron a Nueva York el 13 de junio (47).

Desde el día siguiente, diarios de todo el mundo publicaron su obituario en términos laudatorios y profundamente elegíacos (14). El primero, el de Simon Flexner, en el New York Times, quien le había abierto las puertas de EEUU veintiocho años antes a ese excéntrico individuo oriental que llegaba del otro lado del mundo con las valijas solo cargadas de sueños (16). Mensajes de simpatía y admiración afluyeron a la Fundación Rockefeller desde todo el orbe (14), por cuanto se trataba de una celebridad médica de renombre internacional y su muerte devenía intempestiva, absurdamente cruel y prematura.

Hideyo Noguchi fue inhumado en el cementerio Woodlawn de Nueva York el viernes 15 de junio de 1928. El epitafio de su lápida hasta hoy escuetamente reza: "Through devotion to Science, he lived And DIED FOR HUMANITY" (52).

\section{El legado de Hideyo Noguchi}

La carrera de la consecución de la verdad en la ciencia, resulta obvio, está plagada de errores y de fallos, más que de triunfos o de auspiciosos logros. Noguchi no estuvo exento de traspiés diversos y de hecho, es necesario analizar y tener en cuenta esos gruesos lapsus y entenderlos en su más amplio contexto. La desmesura de la ambición de Noguchi en muchas ocasiones desbordó incluso los límites de la sofisticación tecnológica disponible en su época (muchos de sus fracasos se debieron a la aplicación, bienintencionada pero fallida, de técnicas bacteriológicas estándar a enfermedades que finalmente se revelaron de naturaleza viral, y para las que no existían aún recursos técnicos adecuados en esa circunstancia temporal). Por otro lado, la enorme capacidad de trabajo de Noguchi, en un momento histórico donde la imagen tradicional aún era la del científico solitario, aureolado de genialidad, a la manera de Koch o de Pasteur, se combinó muchas veces negativamente con su excedida necesidad de reconocimiento — probablemente de hondas raíces personales producto de una infancia pletórica de carencias, y que siempre impulsó en él un insaciable hambre de logro- ubicándolo muchas veces en planes de investigación por encima de sus capacidades y de las reales perspectivas de la ciencia, y llevándolo al egotismo, al aislacionismo y la cerrazón, actitudes ajenas y opuestas al desarrollo científico abierto, dialogante y libre.

Como su padre espiritual, Sakae Kobayashi se lo mencionó con clarividencia (16), los principales tres rasgos personales de Noguchi, sus fortalezas nucleares, devenían de su deformidad física, de sus orígenes en la pobreza y de su proverbial terquedad y perseverancia. Cómo lograr positivamente transformar una limitación que podría haber sido motivo de frustración vital y fracaso de la personalidad, en una fuente de motivación y de ascenso espiritual, constituye parte del misterio admirable de la vida de Noguchi: que sin fincarse en el resentimiento él pudiese abrir las alas del ideal para remontar airosamente su propia situación desfavorecida y limitante, tal es una faceta insoslayable de su ejemplo y su legado, más allá de consideraciones mezquinas y menudas.

Todos los pueblos necesitan admirarse en las imágenes tutelares de sus propios hijos más meritorios y victoriosos. En el Japón, la imagen de Noguchi ha salido del ámbito frío y distante de la ciencia para convertirse en un ícono popular de virtudes acendradamente niponas, como un modelo a seguir pero no ajeno ni inalcanzable, sino que ha emergido del penetral mismo del alma japonesa para encarnarla plenamente. Se conserva aún la humilde choza donde nació Noguchi y a su alrededor se ha edificado un vistoso museo consagrado a su memoria (https://www. noguchihideyo.or.jp/) donde se perenniza a través de sus pertenencias materiales el recuerdo de su legado espiritual, elevadamente humano y muestra cabal de las posibilidades de conquista del espíritu. Incluso una réplica robótica tridimensional de Noguchi recibe a los visitantes al museo - la cultura japonesa es aficionada a estos artilugios - y bromea sobre su mano lesionada y sobre su imagen en el billete de 1000 yenes. Es decir, se rescata a un héroe del pueblo, cercano y muy humano, y se lo coloca como inspiración tangible y viva en medio de los niños visitantes del museo. En nuestro país, ¿no podría hacerse algo similar con nuestro 
Daniel Alcides Carrión, o con otros prohombres de la medicina y la ciencia que han quedado relegados entre polillas y olvido histórico?

Como mencionó Theobald Smith, en el obituario de Hideyo Noguchi (54), hay hombres que aparecen a raros intervalos de la historia y cuya originalidad y capacidad de trabajo y creación los distinguen entre todos sus pares, por encima del nivel común. Hideyo Noguchi fue uno de estos individuos. Sus hallazgos del Treponema pallidum como causante de la parálisis general progresiva, al romper el paradigma de la dualidad mente / cerebro en la etiología de la enfermedad mental y abrir paso a los primeros tratamientos fructuosos de la locura, habrían bastado para ubicarlo en un sitial de relieve en la historia de la ciencia biomédica. Su muerte, en medio de su tenaz trabajo de investigación sobre la fiebre amarilla, lo hermana con otros médicos mártires -como nuestro Daniel Alcides Carrión- que sacrificaron su vida igualmente por el conocimiento y en aras de disminuir la porción de sufrimiento y muerte de la humanidad doliente.

La figura de Hideyo Noguchi, por ende, merece columbrarse desde la perspectiva más amplia del ser humano, no solo del hombre de ciencia con sus hallazgos y logros y errores contingentes, sino del hombre como ente espiritual capaz de elevación sobre su circunstancia pedestre y actor y autor de vida ascendente. En ese sentido, el derrotero de Noguchi es una senda abierta para la inspiración y un testimonio pleno de triunfo del espíritu y del ánimo más excelsiórico. El espíritu, como sabemos, no sufre discapacidad, ahí subyace su potencia y su versatilidad: Noguchi fue preclaro, feliz y cumplido ejemplo de ello. A un siglo de su presencia física en Perú, su presencia espiritual legítimamente merece agigantarse entre nosotros.

\section{Correspondencia:}

\section{Lizardo Cruzado}

Instituto Nacional de Salud Mental "Honorio Delgado

- Hideyo Noguchi".

Jr. Eloy Espinoza 709. Urb. Palao. San Martín de

Porres. Lima 15102.

Lima, Perú.

Teléfono: 5116149205

Correo electrónico: lizardo.cruzado.d@upch.pe

Declaración de conflictos de interés: El autor declara no tenerlos.
Financiamiento: Por el mismo autor.

\section{REFERENCIAS BIBLIOGRÁFICAS}

1. Hoffman M. Hideyo Noguchi: under the microscope. Tokyo: The Japan Times; 20 de Julio de 2019. Disponible en: https: //www.japantimes. co.jp/news/2019/07/20/national/history/hideyonoguchi-microscope/\#.XtJKuDDTvDc (Fecha de acceso: 30 de mayo de 2020)

2. Ishikawa H. Dr. Noguchi's journey: a life of medical search and discovery. N Engl J Med. 2005; 353: 2091-2092.

3. Eckstein G. Noguchi. New York: Harper \& Bros; 1931.

4. D'Amelio D. Taller than Bandai mountain: The story of Hideyo Noguchi. New York: Viking Press; 1968.

5. Plesset IR. Noguchi and his patrons. London: Associated University Press; 1980.

6. Kita A. Dr. Noguchi's Journey: A Life of Medical Search and Discovery (trad. Peter Durfee). Tokyo: Kodansha; 2005.

7. Tan SY, Furubayashi J. Hideyo Noguchi (18761928): distinguished bacteriologist. Singapore Med J. 2014; 55:550-551.

8. Mariátegui J. Hideyo Noguchi, la psiquiatría y el Perú. Lima: Editorial Minerva; 1985.

9. Minobe K. Aporte de Hideyo Noguchi a la psiquiatría y a la investigación científica en el Perú. Anales de Salud Mental. 1985; 1: 225 -228.

10. Ichigyu Y. Hideyo Noguchi y el Perú (Obra teatral). Lima: Centro Educativo Peruano Japonés Hideyo Noguchi; 2005.

11. Shimabuku R. 100 años de la visita del Dr. Hideyo Noguchi al Perú y su contribución al estudio de la Enfermedad de Carrión. An Fac med. 2020; 81: 108112.

12. Ruíz-García C. Las biografías médicas: ¿estudio de casos para una introducción (histórica) a la medicina? Asclepio. 2005; 57: 117-124.

13. Laborde-Carranco AA. Japón: una revisión histórica de su origen para comprender sus retos actuales en el contexto internacional. En-clav pen. 2011; 5: 111130.

14. Bendiner E. Noguchi: Many triumphs and a brilliant failure. Hosp Pract (Off Ed). 1984; 19: 222-255.

15. Clark PF. Hideyo Noguchi, 1876-1928. Bull Hist Med. 1959; 33: 1-20.

16. Flexner S. Hideyo Noguchi: A biographical sketch. Science. 1929; 69: 653-660.

17. Nakayama DK. Hideyo Noguchi: Controversial microbe hunter. Pharos Alpha Omega Alpha Honor Med Soc. 2011;74:26-33.

18. Takahashi A. Hideyo Noguchi, the pursuit of immunity and the persistence of fame: a reappraisal. 
Primera centuria de la presencia de Hideyo Noguchi en el Perú.

In: Stapleton DH. Creating a tradition of biomedical research: Contributions to the history of the Rockefeller University. New York: The Rockefeller University Press; 2004. pp. 227-239.

19. Hideyo Noguchi Memorial Association. Life history of Hideyo Noguchi. Tokyo: CabiNet Office; 1999. Disponible en: https://www.cao.go.jp/noguchisho/ english/about/lifehistorydrnoguchi.html (Fecha de acceso: 6 de julio de 2020)

20. Lazo RF. Hideyo Noguchi. Su vida y su obra. Guayaquil: Universidad de Guayaquil; 1985.

21. Morita T. The Lifetime of Dr. Hideyo Noguchi.Tokyo: CabiNet Office; 1999. Disponible en: https://www. cao.go.jp/noguchisho/english/about/ lifetimedrnoguchi.html (Fecha de acceso: 30 de mayo de 2020).

22. Corner GW. A history of the Rockefeller Institute. 1901-1953. New York: Rockefeller Institute Press; 1964.

23. Bartholomew JR. Japanese Nobel candidates in the first half of the Twentieth Century. Osiris. 1998; 13: 228-284.

24. Flexner JT. Maverick's progress. New York: Fordham University Press; 1996.

25. Flexner S, Noguchi H. Snake venom in relation to haemolysis, bacteriolysis, and toxicity. J Exp Med.1902; 6: 277-301.

26. Kawabata T. Funny money. Discordant notes. Tokyo: The Japan Times; 21 de noviembre del 2004. Disponible en: https://www.japantimes.co.jp/ life/2004/11/21/to-be-sorted/discordant-notes/ (Fecha de acceso: 7 de julio de 2020).

27. Pai-Dhungat JV, Parikh F. Hideyo Noguchi Syphilis, Oraya Fever and Leptospira. J Assoc Physicians India. 2015;61:767-768.

28. Duffy JD. General paralysis of the insane: Neuropsychiatry's first challenge. J Neuropsychiatry Clin Neurosci. 1995; 7:243-249.

29. Pérez-Trullén JM, Giménez-Muñoz A, Campello I, Chárlez L. General paresis or Bayle disease. Neurosciences and History. 2015;3:147-153.

30. Noguchi H. Serum diagnosis of syphilis and luetin reaction. Philadelphia: Lippincott Co; 1910.

31. Noguchi H, Moore JW. A demonstration of Treponema pallidum in the brain in cases of general paralysis. $\mathrm{J}$ Exp Med. 1913; 17: 232-238.

32. Bartholomew JR. Toward a history of christian scientists in Japan. En: Doak KM (ed.) Xavier's legacies. Catholicism in modern japanese culture. Vancouver: UBC Press; 2011. pp. 47-63.

33. Cueto M. El regreso de las epidemias. Salud y sociedad en el Perú del siglo XX. Lima: IEP; 2000.

34. Noguchi H. Etiology of Yellow Fever I. Symptomatology and pathological findings of the Yellow Fever prevalent in Guayaquil. J Exp Med. 1919; 29: 547-564.
35. Kantha SS. Hideyo Noguchi's research on yellow fever (1918-1928) in the pre-electron microscopic era. Kitasato Arch Exp Med. 1989; 62: 1-9.

36. Noguchi H, Kligler IJ. Experimental studies on yellow fever in northern Peru. J Exp Med. 1921; 33:239-52.

37. Cámara-Milán P. El Dr. Hideyo Noguchi en Yucatán. Rev Biomed. 2000; 11: 207-212.

38. Cueto M. Excelencia científica en la periferia. Lima: GRADE; 1989.

39. Salinas D. Daniel Alcides Carrión: la teoría unicista. Rev Fac Med. 2016; 64: 93-97.

40. Alarcón GS, Alarcón RD. Alberto Leonardo Barton, las bartonellas y la medicina peruana: logros sólidos, reconocimientos tardíos. $2^{\mathrm{a}}$ ed. Lima: Fondo Editorial Comunicacional del Colegio Médico del Perú; 2017.

41. Noguchi H, Battistini TS. Etiology of Oroya Fever I: Cultivation of Bartonella bacilliformis. J Exp Med. 1926; 43:851-864.

42. Noguchi H. Etiology of Oroya Fever IV: The effect of inoculation of anthropoid apes with Bartonella bacilliformis. J Exp Med.1926; 44: 715-728.

43. Noguchi H, Shannon RC, Tilden EB, Tyler JR. Phlebotomus and Oroya Fever and Verruga peruana. Science. 1928; 68:493-495.

44. Noguchi H, Shannon RC, Tilden EB, Tyler JR. Etiology of Oroya Fever XIV. The insect vectors of Carrion's disease. J Exp Med. 1929; 49: 993-1008.

45. Spier R. The history of the peer-review process. Trends Biotechnol. 2002; 20:367-358.

46. Anonymous. Hideyo Noguchi: the tempestuous microbiologist. JAMA. 1963; 183:134-135.

47. Dolman CE. Hideyo Noguchi (1876-1928): his final effort. Clio Med. 1977;12:131-45.

48. Maco V, Encalada M, Wong C, Marcos LA. Historical aspects of endemic trachoma in Peru: 1895-2000. PLoS Negl Trop Dis. 2016; 10(1):e0004116.

49. Noguera JJ. Hideyo Noguchi y el Tracoma (Inawashiro, Japón, 1876 - Accra, Ghana, 1928). Arch Soc Esp Oftalmol. 2007; 82: 661-662.

50. Noguchi H. A cutaneous reaction in syphilis. J Exp Med.1911; 14: 557-568.

51. Eyrich-Lederer S. Hideyo Noguchi's Luetin experiment and the Antivivisectionists. Isis. 1985; 76:31-48.

52. Koide SS. Hideyo Noguchi's last stand: the Yellow Fever Commission in Accra, Africa (1927-8). J Med Biogr. 2000; 8:97-101.

53. Kobayashi Y. Discovery of the causative organism of Weil's disease: historical view. J Infect Chemother. 2001; 7: 10-15.

54. Smith T. Memorial addresses: Hideyo Noguchi (1876-1928). Bull N Y Acad Med. 1929; 5: 877-886.

Recibido: $10 / 07 / 2020$

Aceptado: 19/08/2020 